\title{
Développement d'une méthode de quantification des ARN messagers par RT-PCR dans les biopsies testiculaires
}

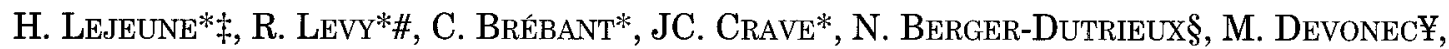 \\ P. Durand $\ddagger$ JM. SAEZ $¥$ M. PugEaT*
}

* Laboratoire de la Clinique Endocrinologique, § Laboratoire d'anatomopathologie, $¥$ Service d'Urologie, Hôpital de l'Antiquaille, \# Laboratoire de Biologie de la Reproduction, Hôpital E. Herriot \& $\ddagger$ INSERM-INRA U418, Hôpital Debrousse, Lyon.

\section{RÉSUMÉ}

Afin de mieux comprendre l'implication des facteurs de régulation de la spermatogenèse en pathologie humailne, nous avons développé une méthode de mesure des ARN messagers (ARNm) par reverse transcription - polymerase chain reaction (RT-PCR), applicable à des fragments testiculaires de petite taille, tels que ceux obtenus lors des biopsies testiculaires. Nous présentons ici les aspects méthodologiques développés pour répondre aux contraintes liées :

- à la taille réduite des échantillons,

- au caractère non renouvelable de la biopsie testiculaire chirurgicale,

- au fait que la pathologie étudiée induit une modification de la composition cellulaire des échantillons (raréfaction des cellules de la lignée germinale).

Les développements méthodologiques ont été effectués à partir des testicules prélevés chez un sujet en état de mort cérébrale (histologie normale) et de 3 testicules pathologiques obtenus lors de castration pour cancer de la prostate et présentant des troubles de la spermatogenèse. Nous avons mesuré l'expression de gènes marqueurs de divers types cellulaires, clusterine pour les cellules de Sertoli, cytochrome $\mathbf{P 4 5 0}$ side chain cleavage (CyP450sce) pour les cellules de Leydig, protamine-1 pour les cellules germinales post-méiotiques ; et d'un facteur para/autocrine testiculaire, la sous unité $\alpha$ de l'inhibine, par rapport à la $\beta$-actine. Les méthodes développées permettent d'obtenir une mesure relative d'un ARNm d'intérêt par rapport à un $A R N m$ de référence à partir de 0,1 $\mu$ g d'ARN total (au lieu de 10-40 $\mu$ g en Northern Blot).

La mesure des ARNm de l' $\alpha$-inhibine dans des ARN testiculaires dilués par des ARN d'une lignée cellulaire n'exprimant pas l' $\alpha$-inhibine (HepG2) montre une bonne corrélation avec les valeurs attendues $(r=0,989 ; p=0,0015)$ et une bonne corrélation entre $R T$ PCR et Northern Blot ( $r=0,995$; $p=0,0005$ ). En comparant l'expression des gènes étudiés dans les échantillons pathologiques par rapport au sujet contrôle, on observe une bonne corrélation entre RT-PCR et Northern blot $(r=0,914 ; p=0,0002)$. Nos résultats concordent avec les constatations histologiques : absence d'expression de la protamine-1 dans les troubles sévères 
de la spermatogenèse, augmentation de l'expression du CyP450sec en cas d'hyperplasie leydigienne. L'expression de l' $\alpha$-inhibine est en relation avec la proportion de cellules somatiques dans les échantillons. Ceci indique la nécessité d'une mesure relative de l'expression des facteurs paracrines, par rapport à des marqueurs spécifiques de chaque type cellulaire du testicule.

Ces méthodes vont permettre des études de l'expression des gènes des facteurs régulateurs de la spermatogenèse sur les biopsies testiculaires réalisées lors des soins de l'infertilité des patients.

Mots-clés : RT-PCR, quantification, ARN messagers, testicule, spermatogenèse, biopsie.

\section{INTRODUCTION}

La physiopathologie des troubles de la spermatogenèse reste très mal connue. Afin de mieux comprendre l'implication des facteurs locaux de régulation de la spermatogenèse en pathologie humaine, nous avons développé une méthode de mesure des $\mathrm{ARN}$ messagers (ARNm) par reverse transcription - polymerase chain reaction (RT-PCR), applicable à des fragments testiculaires de petite taille, tels que ceux obtenus lors des biopsies testiculaires.

Nous présentons ici les aspects méthodologiques développés pour répondre aux contraintes liées :

- à la taille réduite des échantillons,

- au caractère non facilement renouvelable de la biopsie testiculaire chirurgicale en pratique clinique,

- au fait que la pathologie étudiée induit une modification de la composition cellulaire des échantillons.

Les troubles de la spermatogenèse sont caractérisés par une raréfaction des cellules de la lignée germinale dans l'échantillon. Ainsi, on peut assumer que, parmi les ARN extraits des fragments de biopsie testiculaire, la proportion des ARN provenant de chaque type cellulaire du testicule sera variable selon la composition cellulaire de l'échantillon et ainsi selon la pathologie étudiée. Pour analyser les résultats de la quantification des ARNm dans des échantillons pathologiques, nous nous sommes proposés d'utiliser des ARNm spécifiques de divers types cellulaires comme des marqueurs de références.

\section{MATERIEL ET METHODES}

\section{Echantillons tissulaires.}

Les développements méthodologiques ont été effectués à partir des testicules prélevés chez un sujet de 23 ans en état de mort cérébrale. Le prélèvement des testicules a été réalisé avant la parution de la loi bioéthique du 29 Juillet 1994, lors d'études réalisées avec l'accord du comité d'éthique de l'Université Claude Bernard et des Hospices Civils de Lyon [3]. Le parenchyme testiculaire a été congelé et conservé dans l'azote liquide jusqu'à l'extraction des ARN. L'étude histologique a montré un aspect normal du parenchyme testiculaire. Ce sujet sera dénommé sujet contrôle. Les valeurs obtenues chez les autres sujets seront exprimées de manière relative à celles obtenues chez ce sujet. Les testicules obtenus lors des castrations pour cancer de la prostate chez 3 patients présentant les troubles de la spermatogenèse d'intensité variée, ont été congelés et conservés dans l'azote liquide. L'étude histologique a montré les aspects suivants :

- hypospermatogenèse avec production de spermatozoïdes dans moins de $10 \%$ des tubes,

- atrophie parenchymateuse majeure avec fibrohyalinose et involution sertolienne des tubes séminifères, 
- involution hyaline des tubes séminifères avec hyperplasie leydigienne.

\section{Reverse transcription et polymerase chain reaction (RT-PCR)}

L'extraction des ARN totaux a été réalisée par une modification de la méthode de Chomczynski et Sacchi [11], après broyage au polytron des fragments de parenchyme testiculaire congelé. L'étape de reverse transcription a été amorcée par oligodT, ce qui permet l'amplification ultérieure de tous les ARNm à extrémité poly-A. La reverse transcription est réalisée à partir d'1 $\mu \mathrm{g}$ d'ARN total dans un volume de 20 $\mu \mathrm{l}$. La PCR est réalisée à partir de $2 \mu \mathrm{l}$ de produit de reverse transcription, provenant donc de $0,1 \mu \mathrm{g}$ d'ARN total. Les amorces de PCR spécifiques des gènes étudiés ont été choisies de manière à avoir une taille de 20 bases et une composition en CG de $45-55 \%$ CG (Tableau 1). Cette homogénéité des amorces permet d'utiliser des conditions de températures identiques pour tous les gènes étudiés : $1 \mathrm{~min} 3094^{\circ} \mathrm{C}-2 \mathrm{mn} 55^{\circ} \mathrm{C}$ $3 \mathrm{mn} 72^{\circ} \mathrm{C}$. Les amorces de PCR ont été choisies de manière à être situées sur des exons différents, ce qui permet d'éviter l'amplification de l'ADN génomique. Une coamplification de l'ADN complémentaire
(cDNA) d'intérêt et du cDNA de référence a été réalisée dans le même tube, ce qui permet le contrôle de l'absence de dégradation des ARN et évite les variations d'amplification entre les tubes de PCR. Pour éviter qu'une trop grande différence d'expression entre le gène d'intérêt et le gène de référence coamplifié ne gêne la quantification, l'amplification a été décalée avec adjonction des amorces du gène dont l'expression est la plus forte de manière retardée par rapport au début de l'amplification du gène dont l'expression est la plus faible. La révélation des produits de PCR a été réalisée par Southern blot (électrophorèse en gel d'agarose $1 \%$, suivie d'un transfert sous vide sur membrane de Nylon), puis hybridation avec les sondes de cDNA spécifiques des produits amplifiés, marquées au ${ }^{32} \mathrm{P}$ CTP par la méthode d'amorce au hasard (random priming). Après lavage à haute stringence, une autoradiographie a été réalisée à $-70^{\circ} \mathrm{C}$. Cette méthodologie permet une révélation des produits de PCR dont la spécificité est attestée par leur taille et par l'hybridation avec la sonde spécifique. Les images d'autoradiographie sont quantifiées par densitométrie. Ne sont prises en compte que les mesures correspondant à la phase exponentielle d'amplification.

Tableau 1 : Amorces utilisées pour la RT-PCR.

\begin{tabular}{|c|c|c|c|c|}
\hline Gène & & Amorces & $\begin{array}{l}\text { Taille du fragment } \\
\text { (paires de bases) }\end{array}$ & $\begin{array}{l}\text { Référence de } \\
\text { la séquence }\end{array}$ \\
\hline \multirow[t]{2}{*}{ Clusterine } & Sens & 5'-CAGAATTCATACGAGAAGGC-3' & \multirow[t]{2}{*}{330} & Wong et al \\
\hline & Anti-sens & 5'-TAGTACTGGTCTTCGCCTTG-3' & & 1994 \\
\hline \multirow[t]{2}{*}{ CyP450scc } & Sens & 5'-ACATCACCTACTTCCGGAAC-3' & \multirow[t]{2}{*}{122} & Morohashi et al \\
\hline & Anti-sens & 5'-CAACTCTGAAGTTCTCCAGC-3' & & 1987 \\
\hline \multirow[t]{2}{*}{ Protamine-1 } & Sens & 5'-AGGTACAGATGCTGTCGCAG-3' & \multirow[t]{2}{*}{115} & Retief et al \\
\hline & Anti-sens & 5'-CAGCACCTCATGGCTCTCCT-3' & & 1994 \\
\hline \multirow[t]{2}{*}{$\alpha$-Inhibine } & Sens & 5'-GAGGAAGAGGAGGATGTCTC-3' & \multirow[t]{2}{*}{660} & Mason et al \\
\hline & Anti-sens & 5'-CACCATGACAGTAGTGGAAG-3' & & 1986 \\
\hline \multirow[t]{4}{*}{ B-Actine } & Sens "court" & 5'-GACAGGATGCAGAAGGAGAT-3' & \multirow{4}{*}{$\begin{array}{l}166 \\
436 \\
706\end{array}$} & \multirow{4}{*}{$\begin{array}{l}\text { Nakajima- } \\
\text { Iijima et al } \\
1985\end{array}$} \\
\hline & Sens "moyen" & 5'-CTGGACTTCGAGCAAGAGAT-3' & & \\
\hline & Sens "long" & 5'-GCCATGTACGTTGCTATCCA-3' & & \\
\hline & Anti-sens & 5'-GACTCGTCATACTCCTGCTT-3' & & \\
\hline
\end{tabular}


Nous avons mesuré l'expression de gènes marqueurs de divers types cellulaires, la clusterine [10] pour les cellules de Sertoli, le cytochrome $\mathrm{P} 450$ side chain cleavage (CyP450scc) [5] pour les cellules de Leydig, la protamine-1 [7] pour les cellules germinales post-méiotiques ; et d'un facteur para/autocrine testiculaire, la sous unité $\alpha$ de l'inhibine [4], par rapport au gène de référence classiquement utilisé, la $\beta$-actine [6].

\section{Northern Blot}

Les mesures d'ARNm par Northern Blot ont été réalisées comme précédemment décrit [2]. Les ARN totaux ont été extraits par la méthode de Chomczynski et Sacchi modifiée [11], à partir des cellules en culture pour la lignée HepG2 et à partir de fragments de parenchyme testiculaire de taille supérieure $(\approx 100 \mathrm{mg}$ ) à celle des fragments biopsiques, congelés dans l'azote liquide et réduits en poudre à l'aide d'un pilon avant décongélation dans la solution d'extraction des ARN.

\section{RESULTATS}

La figure 1 montre que la fluorescence UV en présence de bromure d'éthidium des produits de PCR a une sensibilité insuffisante pour permettre une révélation dans la zone d'amplification exponentielle. Par contre, l'utilisation de la méthode de Southern blot - hybridation apporte, outre la spécificité, une sensibilité suffisante pour la révélation des produits de PCR pendant la phase exponentielle d'amplification, condition nécessaire pour que le rapport des produits de RT-PCR représente le rapport des ARNm dans l'échantillon initial.

L'effet du décalage de l'amplification des 2 gènes coamplifiés est illustré dans la Figure 2. Cette méthode permet d'éviter que la saturation de l'amplification du gène le plus exprimé ne survienne avant que l'expression du gène le moins exprimé ne soit détectable.

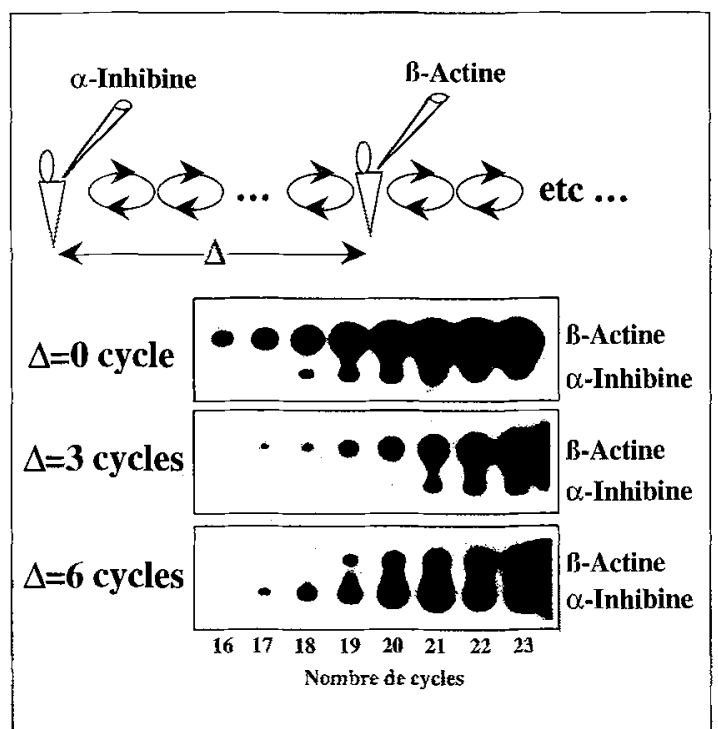

Figure 1 : Coamplification des cDNA de la $\beta$-actine et de la Clusterine obtenus par transcription inverse d'ARN de testicule histologiquement normal. Les produits de PCR ont été prélevés après 12 à 20 cycles d'amplification, séparés par électrophorèse sur gel d'agarose $1 \%$ en présence de bromure d'éthidium et révélés par fluorescence UV (en haut). Les produits de PCR sont détectés en fluorescence $U V$ à partir de 16 cycles. Les produits de PCR ont été transferés du gel sur une membrane de nylon, hybridés avec des sondes de cDNA de la $\beta$ actine et de la Clusterine marquées au ${ }^{32} \mathrm{P}$. Les membranes de nylon ont été lavées à haute stringence $\left(0,1 x \mathrm{SSC} ; 65^{\circ} \mathrm{C}\right)$. L'autoradiographie est présentée au milieu. Le graphique donne les résultats de l'analyse densitométrique de l'autoradiographie et la représentation du taux théorique d'amplification de la PCR. On constate que l'amplification est exponentielle (échelle des ordonnées logarithmique) jusqu'à 16 cycles.

La Figure 3 montre les résultats de la mesure relative des $A R N m$ de l'a-inhibine par rapport à ceux de la $ß$-actine par RTPCR et par Northern Blot sur des solutions d'ARN totaux constituées par mélange en proportion connue d'ARN totaux de testicule humain normal (exprimant l'a-inhibine) et d'ARN totaux d'une lignée cellulaire d'hépatocarcinome humain (HepG2) n'exprimant pas l' $\alpha$-inhibine. Il existe une 
bonne corrélation entre les résultats de la RT-PCR et les valeurs attendues du fait de la dilution $(r=0,989 ; p=0,0015)$ et une bonne corrélation entre RT-PCR et Northern Blot $(r=0,995 ; p=0,0005)$.

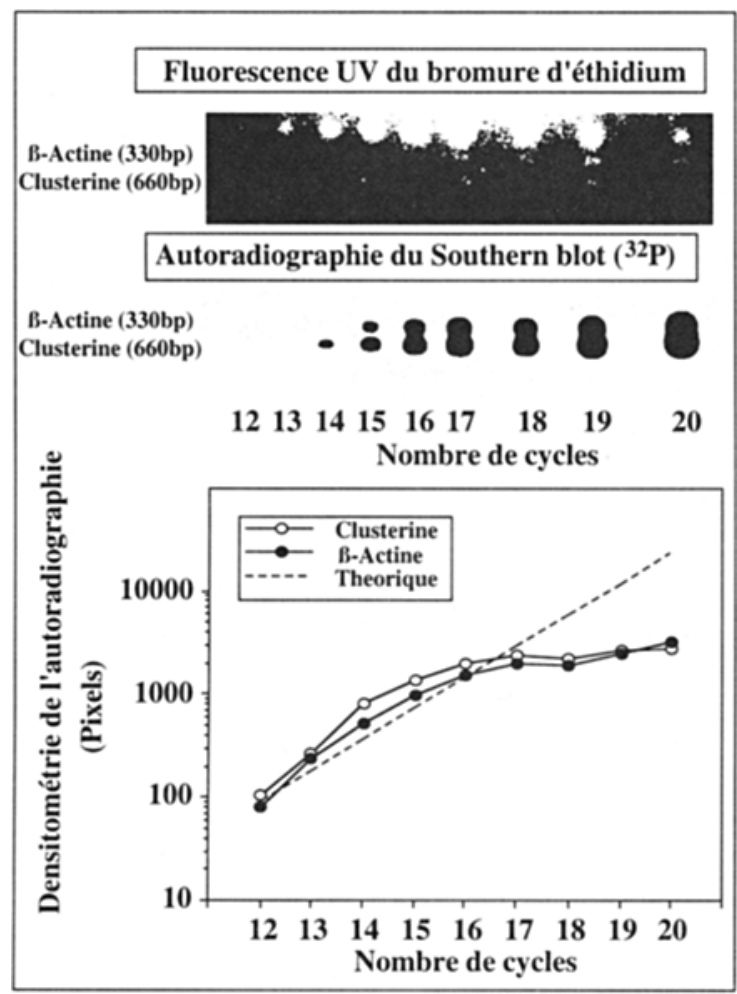

Figure 2 : Influence du décalage du début de l'amplification de la B-actine en coamplification avec l'a-inhibine. En haut, schéma du protocole expérimental. La transcription inverse d'ARN a été réalisée à partir d'ARN total de testicule histologique. ment normal. Les amorces spécifiques de l'a-inhibine ont été mises dans le milieu réactionnel au début de l'amplification par PCR, les amorces de la B-actine ont été mises dans le milieu réactionnel en même temps $(\Delta=0)$ ou avec un décalage de $\Delta=3$ ou 6 cycles. En bas, image des autoradiographies : on observe qu'en absence de décalage, l'image autoradiographique de la $\beta$ actine est saturée lorsque l'image de l' $\alpha$ inhibine devient visible. Le décalage permet d'analyser les 2 produits d'amplification simultanément en phase exponentielle.
En comparant la mesure relative des $\mathrm{ARNm}$ des différents gènes étudiés par rapport aux ARNm de la $\beta$-actine dans les échantillons pathologiques par rapport au sujet contrôle, on observe une bonne corrélation entre RT-PCR et Northern blot $(\mathrm{r}=0,914 ; \mathrm{p}=0,0002)$ (Figure 4). La corrélation des résultats obtenus par RT-PCR réalisées soit à partir d'ARN extrait de fragments biopsiques (1-5 mg) soit à partir des fragments de taille plus importante $(\approx 100$ $\mathrm{mg})$ est aussi satisfaisante $(\mathrm{r}=0,931$; $\mathrm{p}=0,0003$ ).

Les résultats de la mesure des ARNm des gènes considérés comme marqueurs de différents types cellulaires dans le testicule concordent avec les constatations histologiques (Figure 5) : absence d'expression de la protamine-1 dans les troubles sévères de la spermatogenèse, augmentation de l'expression du CyP450scc en cas d'hyperplasie leydigienne. L'expression de l' $\alpha$-inhibine est trouvée augmentée dans les échantillons présentant des troubles de la spermatogenèse et apparaît en relation avec la proportion de cellules somatiques dans les échantillons.

\section{DISCUSSION}

Bien que les altérations de la spermatogenèse soient responsables d'une proportion importante des cas d'infertilité masculine, les données physiopathologiques restent encore parcellaires dans ce domaine. Les faibles quantités de tissus pathologiques disponibles par biopsie testiculaire ont jusqu'ici limité les investigations fonctionnelles dans les troubles de la spermatogenèse. Il est ainsi apparu intéressant d'utiliser la méthode de RT-PCR qui permet l'analyse de l'expression des gènes à partir de quantités très faibles de tissus. Nous présentons ici les résultats de la mise au point méthodologique qui permet une quantification des ARNm dans des fragments de parenchyme testiculaire de petite taille 


\section{Northern blot versus RT-PCR}

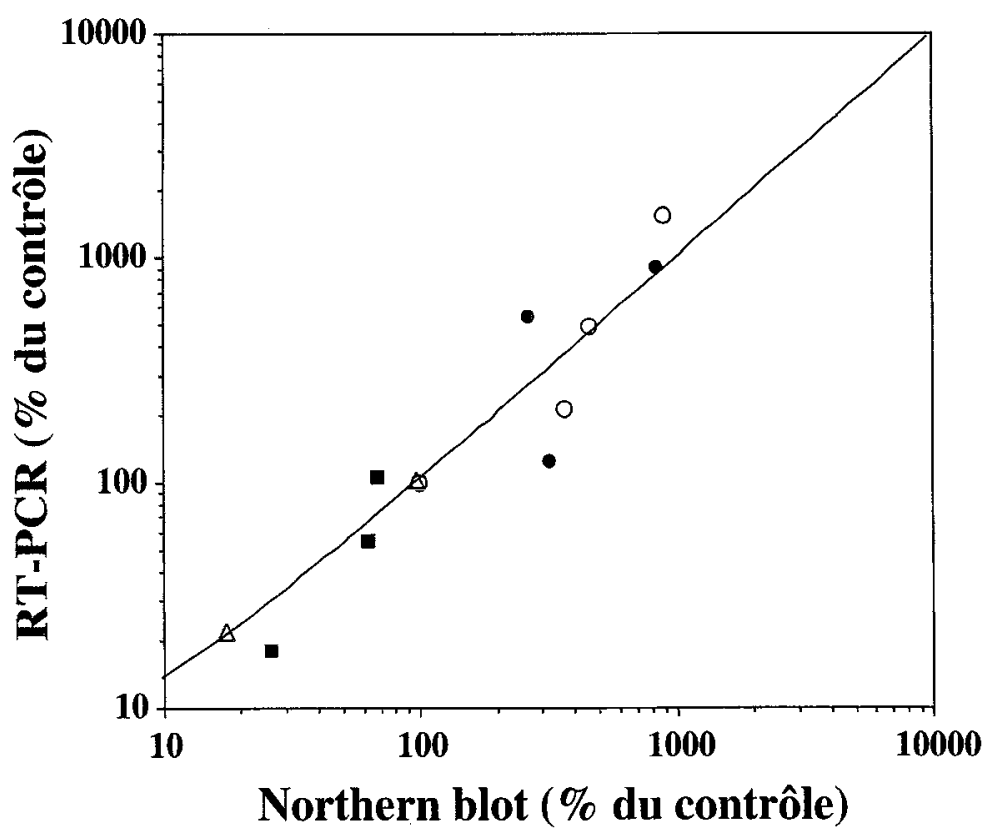

- ARNm Clusterine / ARNm ß-actine

- ARNm $\alpha$-inhibine / ARNm B-actine

○ ARNm CyP450sce / ARNm ß-actine

$\triangle$ ARNm Protamine-1 / ARNm B-actine

Figure 3 : Mesure des ARNm de l'a-inhibine par rapport aux ARNm de la $\beta$-actine par RT-PCR et par Northern Blot. Les échantillons analysés ont été des ARN totaux extraits d'un testicule histologiquement normal (Testicule 100\%), des ARN totaux extraits de cellules de la lignée d'hépatocarcinome humain HepG2 (HepG2 100\%), et d'un mélange des 2 solutions d'ARN totaux selon les proportions indiquées : Testicule 25\%-HepG2 75\%; Testicule 50\%-HepG2 50\% ; Testicule 75\%-HepG2 25\% sur la base de la masse d'ARN total, mesurée par la densité optique à 260nm. Pour chacune des conditions, 1 $\mu \mathrm{g}$ d'ARN total à été utilisé pour la RT, 20 ug pour le Northern blot. A : Image autoradiographique des produits de RT-PCR, $B$ : Image autoradiographique des Northern blots réalisés avec la sonde ainhibine en haut, $\beta$-actine au milieu. En bas est présentée l'image de la fluorescence en $U V$ des ARN sur de la membrane de nylon après électrophorèse en présence de bromure d'éthidium et transfert. $C$ : représentation de la corrélation des rapports ARNm a-inhibine / ARNm B-actine obtenus pour les divers mélanges d'ARN, et mesurés par Northern blot et RT-PCR. Les valeurs sont exprimées en \% du contrôle, c'est à dire en \% de la valeur obtenue pour les ARN de testicule non dilués par des ARN d'HepG2.

telle que ce qui est obtenu lors des biopsies testiculaires. La mise au point méthodologique a été réalisée à l'aide de tissus testiculaires disponibles en plus grande quantité ce qui permet de comparer les résultats de la RT-PCR à ceux de la méthode classique de quantification des ARNm par Northern Blot.
Etant donné les incertitudes physiopathologiques dans les troubles de la spermatogenèse nous avons choisi des méthodes qui peuvent être utilisées pour mesurer l'expression de différents gènes. L'amorce de la reverse transcription par oligodT permet d'utiliser les mêmes produits de RT pour différents ARNm pourvu qu'ils possèdent 
Northern blot versus RT-PCR

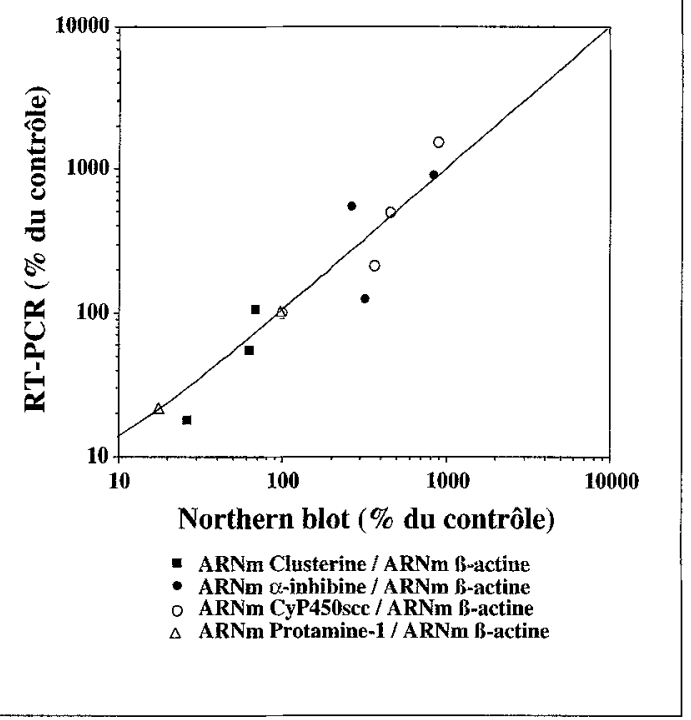

Figure 4 : Corrélation entre les mesures des ARNm par RT-PCR et par Northern Blot, ̀̀ partir d'ARN totaux extraits de testicules de 3 patients présentant des troubles de la spermatogénèse, par rapport un sujet contrôle ayant une histologie testiculaire normale.

une extrémité 3 ' polyadénylée. Pour normaliser les résultats concernant les facteurs étudiés d'un prélèvement à l'autre et pour vérifier l'absence de dégradation des ARN d'un échantillon, nous avons choisi d'utiliser la coamplification du facteur étudié et d'un gène ubiquitaire à expression non régulée [1] comme la $\beta$-Actine [6]. La méthode développée permet d'obtenir une mesure relative d'un ARNm d'intérêt par rapport à un $\mathrm{ARNm}$ de référence à partir de $0,1 \mu \mathrm{g}$ d'ARN total au lieu de 10-40 $\mu \mathrm{g}$ en Northern Blot. Les fragments biopsiques permettant d'obtenir de 2 à $10 \mu \mathrm{g}$ d'ARN total, on peut effectuer une quantification de 20 à 100 gènes. Les expériences de comparaison des mesures des ARNm par RTPCR et par Northern blot donnent des résultats satisfaisants si on en juge par les corrélations significatives avec coefficients de corrélation supérieurs à 0,9 . L'expérien- ce de dilution d'ARN testiculaire par de l'ARN d'une lignée n'exprimant pas le gène mesuré montre la bonne corrélation avec les valeurs théoriques attendues.

L'interprétation physiologique des résultats de mesure de ARNm dans les biopsies testiculaires est rendue délicate du fait des nombreux types cellulaires présents dans le testicule. Nous avons choisi pour cette étape de mise au point méthodologique des échantillons permettant de juger des variations des marqueurs de certains types de cellules testiculaires selon l'importance de la déplétion en cellules germinales, c'est à dire en fonction de l'intensité du trouble de la spermatogenèse. Comme attendu, l'expression de la protamine-1 qui est spécifique des cellules germinales post-méiotiques n'est pas trouvée dans les échantillons présentant des troubles intenses de la spermatogenèse avec absence de cellules germinales post-méiotiques et est diminuée en cas d'hypospermatogenèse. L'expression du cytochrome P450scc, enzyme de la stéroïdogénèse spécifique des cellules de Leydig, augmente en fonction de la déplétion relative en cellules du tube séminifêre. Son expression est maximale dans le cas d'hyperplasie leydigienne comme attendu. Les ARNm de la clusterine ont été choisis comme marqueurs Sertolien car ce gène est fortement exprimé dans les cellules de Sertoli et son expression a été trouvée indépendante de l'état hormonal et de la présence de cellules germinales chez le rat. [8]. On trouve une relation entre l'expression de la clusterine et l'aspect des tubes séminifères. Une étude plus précise des variations de l'expression de la Clusterine selon le rapport entre les cellules de Sertoli et les cellules germinales dans les tubes séminifères devra être conduite. L'expression de la sous-unité $\alpha$ de l'inhibine est trouvée paradoxalement augmentée dans les cas de trouble de la spermatogenèse par rapport au sujet normal. Il semble que la proportion d'ARNm de la sous-unité $\alpha$ de l'inhibine soit augmentée dans ARN totaux testicu- 


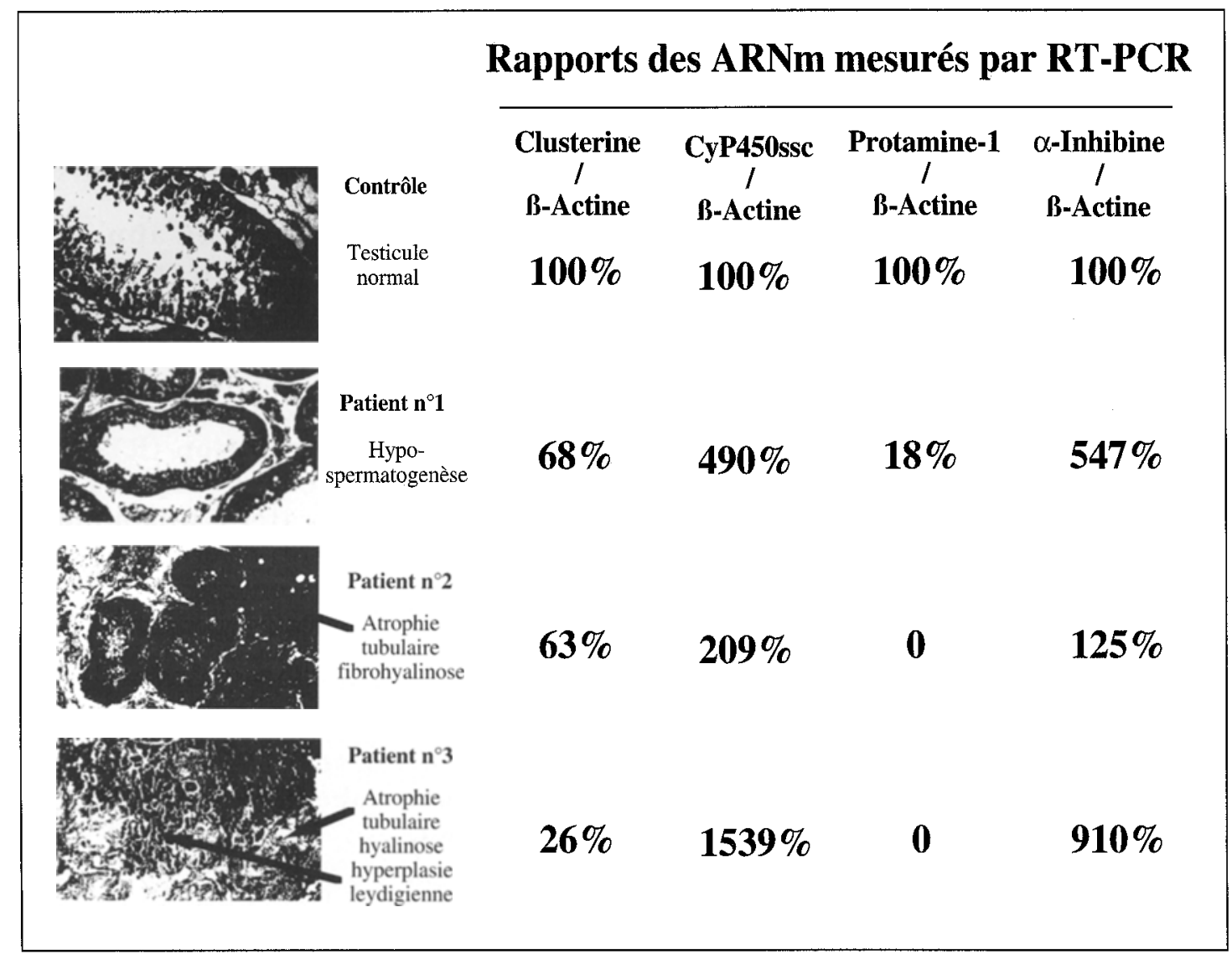

Figure 5 : Relation entre mesure des ARNm par RT-PCR et histologie testiculaire. La mesure des différents $A R N m$ étudiés, rapportée aux $A R N m$ de la $\beta$-actine, a été exprimée de manière relative au résultat obtenu pour le sujet contrôle dont l'histologie testiculaire est normale.

laires lors de la raréfaction des cellules germinales dans les troubles de la spermatogenèse. Les valeurs élevées d'ARNm trouvées dans le cas de l'hyperplasie leydigienne suggèrent fortement une expression de la sous-unité $\alpha$ de l'inhibine dans les cellules de Leydig comme cela a été montré pour les cellules de Leydig de rat adulte [9]. Ces résultats indiquent clairement la nécessité d'une mesure relative de l'expression des facteurs paracrines, par rapport à des marqueurs spécifiques de chaque type cellulaire du testicule, dans les troubles de la spermatogenèse. Une approche complémentaire permettant de préciser la localisation cellulaire des ARNm quantifiés par la PCR sera nécessaire pour une compréhension complè- te des modifications fonctionnelles au cours des troubles de la spermatogenèse. Hybridation in situ et mesure des ARNm par RTPCR nous apparaissent des méthodes complémentaires.

Ces méthodes vont permettre des études de l'expression des gènes des facteurs régulateurs de la spermatogenèse sur les biopsies testiculaires des patients présentant des troubles de la spermatogenèse.

Ce travail a été financé par le Réseau de Recherche Clinique INSERM $n^{\circ}$ 493010, la Commission Recherche des Hospices Civils de Lyon et le Ministère de la Santé (Projet National de Recherche Clinique). Les auteurs remercient la Société d'Andrologie de Langue Française pour le Prix de Poster accordé à ce travail lors du 


\section{REFERENCES}

1. CHELLY J., KAPLAN J.C., MAIRE P., GAUTRON S., KAHN A. : Transcription of the dystrophin gene in human muscle and non-muscle tissues. Nature, 1988, $333: 858-860$.

2. CRAVE J.C., LEJEUNE H., BRÉBANT C., BARET C., PUGEAT M. : Differential effects of insulin and insulin-like growth factor-1 on the production of plasma steroid-binding globulin by human hepatoblastoma-derived (Hep G2) cells. J. Clin. Endocrinol. Metab., 1995, 80 : 1283-1289.

3. LEJEUNE, H., SKALLI, M., SANCHEZ, P., AVALLET, O., SAEZ, J.M. : Enhancement of testosterone secretion by normal adult human Leydig cells by coculture with enriched preparations of normal adult human Sertoli cells. Int. J. Androl., 1993, 16 : 27-34.

4. MASON AJ, NIALL HD, SEEBURG PH. : Structure of two human ovarian inhibins. Biochem. Biophys. Res. Comm., 1986, 135 : 957-964.

5. MOROHASHI K, SOGAWA K, OMURA T, FUJIIKURIYAMA Y. : Gene structure of human cytochrome P-450(SCC), cholesterol desmolase. J. Biochem. 1987, 101 : 879-887.

6. NAKAJIMA-IIJIMA S, HAMADA H, REDDY P, KAKUNAGA T. : Molecular structure of the human cytoplasmic $B$-actin gene: Interspecies homology of sequences in the introns. Proc. Natl. Acad. Sci. U.S.A., 1985, 85 : 6133-6137.

7. RETIEF JD, WINKFEIN RJ, DIXON GH, et al. Evolution of protamine $\mathrm{p} 1$ genes in primates. J. Mol. Evol., 1993, 37 : 426-434.

8. ROBERTS KP, SANTULLI R, SEIDEN J, ZIRKIN $B R$. The effect of testosterone withdrawal and subsequent germ cell depletion on transferrin and sulfated glycoprotein-2 messenger ribonucleic acid levels in the adult rat testis. Biol. Reprod., 1992, $47: 92-96$.

9. RISBRIDGER GP, CLEMENTS JA, ROBERTSON $\mathrm{DM}$ et al. Immuno- and bioactive inhibin and inhibin a-subunit expression in rat Leydig cell cultures. Molec. Cell. Endocrinol., 1989, 66 : 119-122.

10. WONG P, TAILLEFER D, LAKINS J, PINEAULT J, CHADER G, TENNISWOOD M. : Molecular characterization of human TRPM-2/clusterin, a gene associated with sperm maturation, apoptosis and neurodegeneration. Eur. J. Biochem., 1994, $221: 917-925$.

11. XIE W.Q., ROTHBLUM L.I. Rapid, small-scale RNA isolation from tissue culture cells. BioTechniques, 1991, $11: 325-327$.
H. LeJeune, R. LeVy, C. BRÉBANT, JC. Crave, N. Berger-Dutrieux, M. Devonec, P. Durand, JM. Saez, M. Pugeat

The physiopathology of abnormal spermatogenesis in infertile men remain largely unknown. To analyse gene expression in the testis, we developped a method of relative quantification of mRNA by reverse transcriptase polymerase chain reaction (RT-PCR), suitable for testicular biopsies. The methodological strategy was adapted to the constraints due to :

- the small size of the tissue samples and

- the modification of the cellular composition of the tissue by the pathological state itself i.e. reduction of germ cell number by the spermatogenic defect.

Preliminary experiments were performed using testes obtained from one 23 years old subject in recent cerebral death (normal spermatogenesis on histological examination) and 3 patients with prostate cancer with the following histological findings : hypospermatogenesis with production of spermatozoa in less than $10 \%$ of the seminiferous tubule sections, seminiferous tubule atrophy with fibrohyalinose, or with hyalinose and Leydig cell hyperplasia.

We measured mRNA levels of genes considered as markers of different cell types, Clusterin for Sertoli cells, cytochrome $P 450$ side chain cleavage (CyP450sec) for Leydig cells and protamine-1 for germ cells, and inhibin asubunit as paracrine/endocrine factor, relatively to the wide-spread used gene of reference $\beta$-actin.

The chosen methods were as follows : 
total RNA extraction, priming of the RT with oligo-dT, primer for PCR of similar composition (20-mer, $45-55 \%$ CG), located on different exons, coamplification of the cDNA of interest with the cDNA of reference in the same PCR tube, delayed begining of amplification of the highest expressed gene to avoid a too high difference in the mRNA levels of the two coamplified cDNAs, revelation of PCR products by Southern blot and hybridization with 32P. CTP labelled probes, autoradiography and densitometry of the signals obtained during the exponential phase of the amplification. Such a procedure allowed to measure the mRNA of interest relatively to the mRNA of reference with $0.1 \mu \mathrm{g}$ of total RNA (instead of 10. $40 \mu \mathrm{g}$ for Northern blot).

The measurement by RT-PCR of inhibin a-subunit mRNAs in testicular RNAs mixed with known amounts of RNAs extracted from a human hepatoma cell line which did not express inhibin $\alpha$-subunit gene (HepG2), was in good correlation with the expected values $(r=0.989 ; p=0.0015)$, as well as with Northern blot values ( $r=0.995$; $p=0.0005$ ). The results of mRNA measu- rement by RT-PCR in the pathological testes, relatively to the normal testis, were in good correlation with Northern blot $(r=0.914 ; p=0.0002)$, and results of RT-PCR performed from small biopsy tissue samples (1-5 mg) and from larger tissue samples $(\approx 100$ $\mathrm{mg})$ were in good correlation ( $\mathrm{r}=0.931$; $p=0.0003$ ). Our results are consistant with histological findings : lack of protamine- 1 expression in the cases of total spermatogenic failure and increased CyP450sce in Leydig cell hyperplasia. The inhibin a-subunit mRNA levels were mainly dependant on the content of the samples in somatic cells of the testis. Our results underline that the use of specific markers of the different cell types is required to give a physiopathological significance to the measurement of the paracrine factor mRNAs in case of spermatogenic defects.

These methods will allow to study the expression of genes involved in the local control of spermatogenesis in small testicular biospies.

Keywords : RT-PCR, quantification, messager RNA, testis, spermatogenesis, biopsy. 